УДК 372.48

DOI: 10.23951/1609-624X-2020-1-16-23

\title{
АНАЛИЗ РАЗВИТИЯ МЕЖДУНАРОДНОЙ ОБРАЗОВАТЕЛЬНОЙ ПРОГРАММЫ И ТЕХНОЛОГИИ «STEP ВY STЕР» В ЗАРУБЕЖНОЙ И ОТЕЧЕСТВЕННОЙ ТЕОРИИ И ПРАКТИКЕ
}

\author{
Е. С. Никитина \\ Томский государственный педагогический университет, Томск
}

\begin{abstract}
Введение. Исследуется актуальная проблема развития международной образовательной программы «Step by Step». Проведенный анализ социологических, психологических, педагогических, методических работ известных отечественных и зарубежных ученых и практиков позволил рассмотреть историко-педагогические аспекты проблемы развития данной программы как за рубежом, так в России и Казахстане.

Материал и методы. Исследование проводилось на основе использования теоретических и эмпирических методов, основным из которых был анализ взаимодействия участников образовательного процесса, а материалом исследования послужили уроки естественно-математического цикла в начальной школе. Данная работа проводилась в три этапа. Первый этап заключался в определении основных теоретико-методологических положений для постановки проблемы, проанализирована степень ее изученности, определены общие положения. Второй этап состоял в выявлении особенностей применения «Step by Step» в классно-урочной модели начальной школы. Tретий этап заключался в анализе результативности обучения детей с применением технологии «Step by Step».

Результаты и обсуждение. Проведенный сравнительный анализ позволил рассмотреть историко-педагогические аспекты проблемы развития данной программы за рубежом, в России и Казахстане, а также обосновать правомерность употребления термина технология применительно к «Step by Step». Представленный анализ понятий «технология», «образовательная технология», «педагогическая технология» доказывает возможность употребления термина «технология» относительно «Step by Step». Большое внимание уделяется проблеме социальной компетентности современного ученика начальной школы и ее развитию в условиях начальной школы.

Заключение. Историко-педагогический анализ развития «Step by Step» позволяет понять суть и основную идею данной технологии. Цель образовательного процесса заключается в развитии личности ребенка, ее индивидуальности, неповторимости на основе убеждения и веры, с учетом особенностей собственной «внутренней модели мира», структуры его субъективного опыта, где субъектные отношения построены на принципах индивидуализации сотрудничества, партнерства и свободы выбора деятельности. Применение технологии «Step by Step» повышает ценность обучения за счет принципиально нового демократичного подхода, соответствующего нормам сегодняшнего дня и содействующего динамичному сотрудничеству всех сторон образовательного процесса, во время которого происходит и совершенствование отдельно взятого индивида.
\end{abstract}

Ключевые слова: технология, международная программа, сравнительный анализ, «Step by Step», начальная школа.

\section{Введение}

В XXI в. приоритетные ценности образования изменились от абсолютного формирования знаний и навыков до развития способностей (способов действия), поэтому инновационные образовательные технологии очень актуальны, позволяя совершенствовать систему образования в демократическом направлении. На сегодняшний день существует огромное количество инновационных образовательных технологий. Начиная работу в этом направлении, мы столкнулись с проблемой: в одной научной педагогической литературе «Step by Step» называют программой, в другой - технологией. Нам кажется действительно важным проанализировать историю становления и развития программы «Step by Step» («Шаг за шагом»), выяснить правомерность употребления термина «технология» по отношению к ней. Цель настоящей работы - изучение как иностранных, так и отечественных исследований в области начального школьного образования с применением программы «Step by Step» (название в России «Сообщество»). Исследование в большей степени проводилось в рамках программы «Step by Step», вследствие этого видится логичным совершить небольшой экскурс в ситуацию становления, развития и преобразования данной образовательной программы.

\section{Материал и методы}

В контексте историко-педагогического анализа известно, что экономическая ситуация в России середины 90-х годов - снижение бюджетных ассигнований на воспитание и образование, недоступность действенных механизмов, позволяющих возмещать недостаток муниципальных средств, явились теми причинами, которые содействовали интенсификации процессов децентрализации управления и финансирования системы образования.

Именно в этот период международные донорские организации (ЮНЕСКО, ЮСАИД, ЮНИСЕФ, ТАСИС, Фонд Сороса и др.) активно поддерживали и инвестировали систему образования рес- 
Никитина Е. С. Анализ развития международной образовательной программын..

публики. Одним из таких проектов стала реализация в России и Казахстане Международной образовательной программы «Step by Step», запущенной Институтом открытого общества в партнерстве с Институтом развития ребенка (CRI, CША).

Становление Международной образовательной программы «Step by Step» впервые началось в 1993 г., при встрече известного инвестора и филантропа Дж. Сороса, основателя Института Открытого Общества (ИОО), с канадским психиатром Фрейзером Мустардом. В проекте дошкольного образования Сороса (тогда он все еще так назывался) была разработана модель целостного воспитания ребенка и оказания помощи его семье в сотрудничестве с образовательными учреждениями, медицинскими и социальными службами.

Данный проект был нацелен на разработку модели дошкольного образования, ориентированной на ребенка, и внедрение новых подходов в существующую государственную систему подготовки педагогических кадров.

Для запуска данного проекта перед персоналом Департамента по работе с детьми и молодежью Института Открытого Общества была поставлена задача разработки программы. Элизабет Лоран (директор данного Департамента) привлекла к этому проекту экспертов, работающих над американской программой «Head Start» на базе Джорджтаунского университета. Командой, работающей над проектом, программа была разделена по трем основным критериям: оценка существующей ситуации в системе раннего и дошкольного образования в странах-участниках; использование накопленного опыта и исследований американской программы «Head Start» [1]; роль Института Открытого Общества в формировании активного гражданского общества.

Подобно программе «Head Start» в Соединенных Штатах Америки этот проект был разработан для обеспечения доступа к системе образования детей, находящихся в зоне риска.

Проект первоначально назывался «Дошкольный проект Фонда Сороса» и представлял собой двухлетний проект, который должен быть реализован в 15 странах Центральной и Юго-Восточной Европы и ориентирован на детей дошкольного возраста с широким привлечением родителей в процесс обучения и воспитания. Разработчики данного проекта: П. Коглин - исполнительный директор «Чилдренс Рисорсиз Интернэшнл» и группа ученых Джорджтаунского университета К. Уолш, Р. Кауфман, Б. Шварц и др. Авторы проекта уверены в том, что дети дошкольного возраста под руководством педагогов способны сделать правильный выбор, понять возможные последствия своих действий и с уважением относиться друг другу, несмо- тря на существующие различия. Ими была разработана оригинальная методика обучения детей в возрасте от 3 до 6 лет, которая успешно внедряется в системе дошкольного образования и воспитания в странах, участвующих в реализации проекта [2]. В самом начале проекта предполагали ограничиться организацией одной показательной группы в каждой стране. Однако выяснилось, что команды в этих странах с энтузиазмом восприняли новые методы, которые отвечали их академическим стандартам. Пятнадцать стран изъявили активное желание присоединиться к данной программе. Первая группа воспитателей раннего детского образования и учителей начальных классов прошла в Соединенных Штатах Америки шестинедельный специализированный тренинг. Летом 1994 г. представители Американского образовательного центра посетили каждую страну, участвующую в программе подготовки директоров дошкольных учреждений, семейных координаторов, учителей, воспитателей и их ассистентов, вспомогательного персонала. Фактически они были первыми иностранцами, встретившимися со специалистами по проблемам раннего детства и обучения на начальной ступени в министерствах образования и науки стран-участниц.

В сентябре 1994 г. 252 класса в государственных школах распахнули свои двери, чтобы принять детей и их родителей в атмосферу обучения, ориентированную на ребенка. Стратегия программы предполагала ее повторение после завершения проекта, поскольку рассматривался вариант, когда дошкольные образовательные учреждения выступят в новом качестве как обучающие центры для вузов, колледжей, готовящих педагогические кадры. В действительности расширение планов было проведено в рамках первого года работы как ответ на запросы директоров, учителей и родителей, представлявших Команду страны на первой встрече в декабре 1994 г. [3].

На следующей встрече в сентябре 1995 г. Команды стран рассматривали новые требования родителей о внедрении программы в начальную школу. В связи с этим было принято новое название «Step by Step» (конкурс выиграла Македония), которое отражало продолжение программы и ее ступенчатый подход к реформам образования. Первоначальная методология и учебное руководство, сопровождающее ее, были переработаны. В каждой стране был привлечен опытный персонал из начальной школы. Сотрудников направили в Соединенные Штаты Америки на 2-недельный курс обучения с посещением школ. В сентябре 1996 г. 179 первых классов открылись в начальных школах, расположенных рядом с экспериментальными дошкольными образовательными учреждениями. 
В последующие годы проект обеспечил подготовку учителей, работающих с первого по четвертый классы [4]. И именно в этот период начинается становление «Step by Step» в качестве не только программы, но и технологии в начальной школе.

В 1998 г. это предложение было принято лидерами программ «Step by Step» и Институтом развития ребенка, в результате появилась необходимость создания постоянной организации поддержки развития новых национальных НПО и возможность организации специалистов, внедряющих ориентированные на ребенка методы обучения [5]. OSI поддержала самоорганизацию сети. В октябре 1998 г. Международная ассоциация «Step by Step» (ISSA) была формально учреждена на Ассамблее в г. Дубровник (Хорватия) и зарегистрирована в Нидерландах, где директором избрана Сара Клаус.

В 2000 г. Институт развития ребенка организовал исследование деятельности неправительственных организаций в четырех странах (Казахстан, Молдова, Украина, Кыргызстан). Участники проведения независимой оценки пришли к выводу, что все новые неправительственные организации «Step by Step», несмотря на трудности, вызванные экономической и политической неопределенностью, несомненно, обладают способностью в будущем продолжить реализацию Международной образовательной программы «Step by Step», а также имеют перспективы для долгосрочного существования.

ISSA претворяет в жизнь различные инновационные проекты реформирования системы образования, которые базируются на принципе ориентации на ребенка и прямого вовлечения сообщества в процесс образования (рис. 1).

В 1997 г. была разработана дополнительная программа для начальной школы, организованы семинары для преподавателей высшей школы, опубликована книга «Культура демократии и дошкольное образование».

В 1998 г. по данной программе было обучено более 800 человек: преподаватели вузов, колледжей, ИПК, специалисты отдела образования, методисты и семейные координаторы. В том же году началась работа по созданию региональных центров по обучению и проведению тренингов: в Усть-Каменогорске, Астане, Новосибирске, Москве и Новокузнецке. Материалы по развитию программы стали публиковаться на страницах республиканского журнала в Казахстане «Отбасы және балабақша», а в России программа получила название «Сообщество», что дало возможность широкой педагогической общественности знакомиться с методологией «Step by Step» [6].

Таким образом, «Step by Step» является программой, предполагающей последовательную реализацию ее принципов на этапе дошкольного раз- вития и обучения, а также реализацию принципов преемственности обучения между детским садом и начальной школой. Говоря же об обучении в начальной школе, имеется в виду технология «Step by Step», так как рассматривается реализация принципов программы только в начальной школе с использованием классно-урочной модели. Для выявления сущности изучения проблемы считаем необходимым остановиться более подробно на понятиях «технология», «образовательная технология», «педагогическая технология».

Словарь иностранных слов трактует определение технологии следующим образом: в переводе с греческого «Тесhnе - искусство, мастерство, умение и логия - совокупность методов обработки, изготовления, изменения состояния, свойств и формы объекта» [7].

В толковом словаре термин «технология» определяется как набор техник, используемых в любом бизнесе, навыке.

Определение «образовательная технология» в «Глоссарии современного образования» рассматривается с трех сторон: 1) систематический метод планирования, применения, оценивания в целом хода преподавания и освоения знаний при помощи учета промышленных и человеческих ресурсов и взаимодействия меж ними с целью улучшения более действенной формы образования; 2) реализация дидактических задач в русле управления учебным процессом с точно заданными целями, достижение которых должно поддаваться точному описанию и определению (общепринятое определение 70-х годов); 3) выявление принципов и разработка приемов оптимизации образовательного процесса путем анализа факторов, повышающих образовательную эффективность, с помощью конструирования и применения приемов и материалов, а также посредством применяемых методов [8].

М. А. Чошанов утверждает, что технология является процедурной категорией; это может быть представлено как комбинация методов изменения состояния. Технология направлена на разработку и использование эффективных и экономичных процессов. [9].

В. А. Сластенин и Н. Г. Руденко трактуют понятие «технология обучения» как педагогическую деятельность, направленную на реализацию научно обоснованного проекта дидактического процесса. Эта педагогическая деятельность обладает более высокой степенью эффективности, надежности и гарантированного результата, чем в случае с традиционными методами обучения [10].

В данной трактовке авторами, во-первых, дается инструкция о совместной деятельности учителя и ученика, что собственно предполагает фактическое отрицание программирования лишь только 
Никитина Е. С. Анализ развития международной образовательной программын..

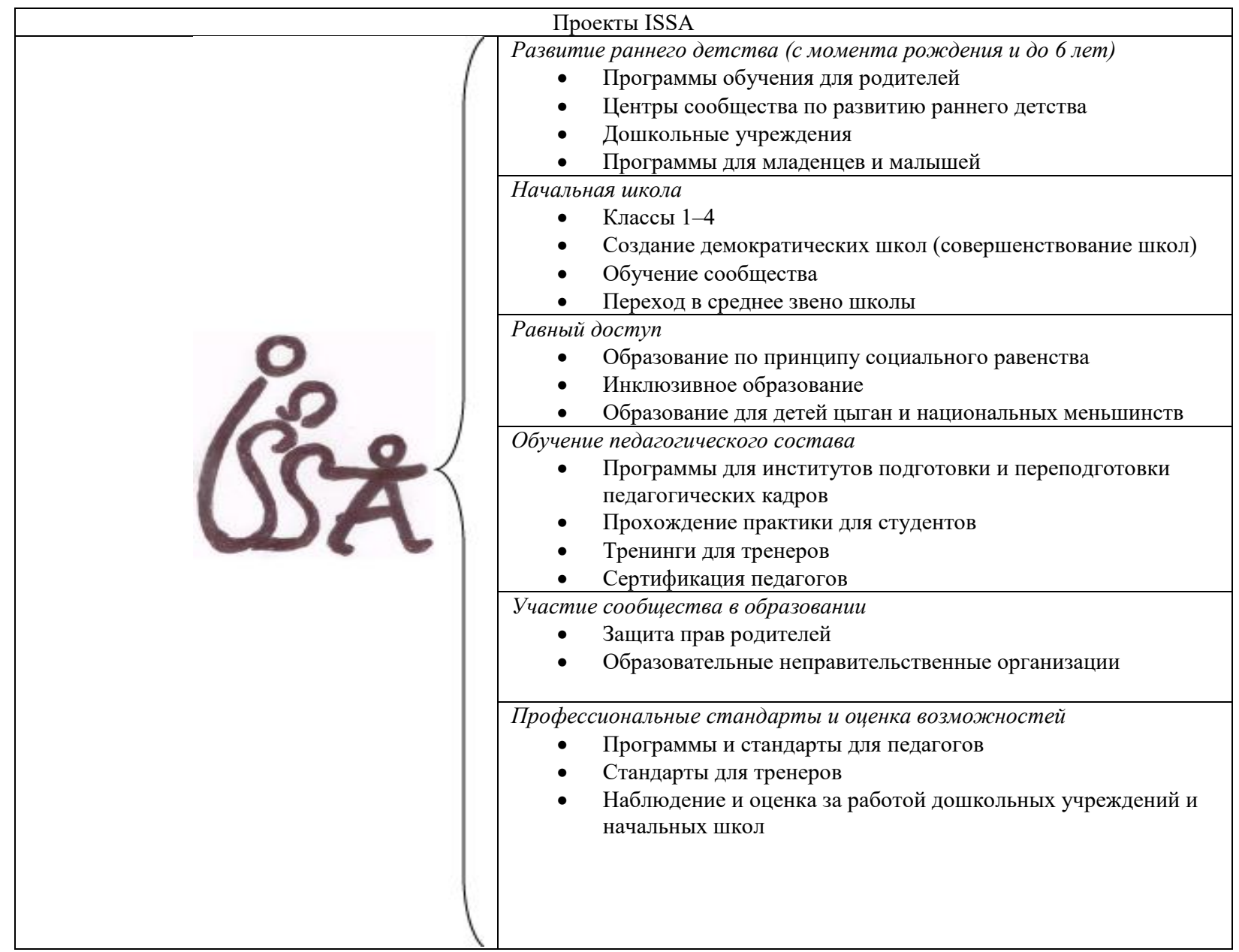

Рис. 1. Проекты ISSA

учителем конечных итогов и построение им точной программы деятельности ученика для их достижения. Другими словами, речь идет о ребенке как о предмете обучения, определяющем как конечные результаты его деятельности, так и процесс их достижения.

Во-вторых, в приведенных выше определениях фиксируется полный цикл управления школьной деятельностью учащихся. В связи с этим можно констатировать, что технология обучения предназначена для обеспечения обучения школьников навыкам самоуправления.

В-третьих, определение привлекает внимание к созданию комфортной среды для деятельности субъектов образовательного процесса, которая ориентирует в первую очередь учителей на поиск и создание условий для раскрытия, реализации и развития личностного потенциала младшего школьника [11-13].

С позиции управления образовательный процесс представляет сочетание самоуправления и управленческой деятельности учителя как взаимодействие участников образовательного процесса и ученика в частности в целостном управленческом цикле.
Педагогическая технология - есть область исследования тесной практики (в рамках системы образования), имеющая связи со всеми сторонами организации педагогической системы для достижения специфических и потенциально воспроизводимых педагогических результатов (П. Митчелл [14]).

Педагогическая технология - это содержательная техника реализации учебного процесса (В. П. Беспалько [15]).

Педагогическая технология - это систематический метод создания применения и определения всего процесса преподавания и обучения с учетом технических и человеческих ресурсов и их взаимодействие, ставящий своей задачей оптимизацию форм образования (ЮНЕСКО).

Из приведенных определений можно вычленить следующие характеристики технологии:

- двусторонний процессуальный характер взаимосвязанной деятельности учителя и учащихся;

- совокупность приемов, методов, проектирования и организации процесса;

- наличие комфортных условий. 
Таким образом, анализ понятий «технология», «образовательная технология» и «педагогическая технология〉 послужил основанием для выдвижения рабочего определения образовательной технологии «Step by Step» так: образовательная технология «Step by Step» - это система совместных действий учителей и детей по разработке, планированию, организации, ориентации и корректировке действий для достижения конкретных результатов при обеспечении комфортных психолого-педагогических условий.

С целью анализа результативности обучения детей с применением технологии «Step by Step» было проведено исследование. Одним из показателей результативности является академическая успеваемость учащихся. Проводимый эксперимент содержал несколько этапов. Целью первого этапа констатирующего эксперимента было определение исходного уровня академической успеваемости по предметам естественно-математического цикла у учащихся начальной школы.

В исследовании приняли участие 497 учащихся контрольной и экспериментальной групп. Сформированные контрольные и экспериментальные группы были практически одинаковы в количественном и качественном отношении.

Для определения качества обучения были проведены контрольные работы. Контроль проводился с целью выявления уровня соответствия знаний, умений и навыков каждого ребенка требованиям ГОСО [16].

В качестве основного материала использовались диагностические контрольные работы. Итоги входной диагностики по основным предметам начальной школы («Математика», «Познание мира», «Русский язык», «Литературное чтение») представлены в таблице 1 .

\begin{tabular}{|c|c|c|c|c|c|c|c|}
\hline \multicolumn{8}{|c|}{$\begin{array}{c}\text { Результатьл контрольного } \\
\text { на начальном этапе }\end{array}$} \\
\hline $\begin{array}{l}\text { оличе- } \\
\text { ство } \\
\text { уча- }\end{array}$ & $\begin{array}{c}\text { Количест- } \\
\text { во учащих- } \\
\text { ся, }\end{array}$ & \multicolumn{4}{|c|}{$\begin{array}{c}\text { Результат } \\
\text { выполнения } \\
\text { работ }\end{array}$} & \multirow{2}{*}{$\begin{array}{l}\text { Успевае- } \\
\text { мость, \% }\end{array}$} & \multirow{2}{*}{$\begin{array}{c}\text { Каче- } \\
\text { ство, } \\
\%\end{array}$} \\
\hline $\begin{array}{c}\text { в } \\
\text { руппе }\end{array}$ & $\begin{array}{c}\text { ших } \\
\text { работу }\end{array}$ & $\mid\langle 5 »\rangle$ & «4» & «3» & «2» & & \\
\hline 148 & 148 & 30 & 52 & 58 & 8 & 94 & 55 \\
\hline 149 & 149 & 30 & 52 & 60 & 7 & 94 & 56 \\
\hline
\end{tabular}

Таким образом, полученные результаты констатирующего этапа экспериментальной деятельности указывают на необходимость проведения целенаправленной работы по повышению уровня успеваемости и качества знаний в условиях классноурочной модели обучения с использованием технологии «Step by Step». В связи с этими положения- ми на следующем этапе эксперимента разработаны и апробированы краткосрочные планы с использованием технологии «Step by Step». Они должны способствовать увеличению в классах высокого уровня успеваемости и качественной обученности и, соответственно, снижению до минимума низкого. Суть технологии «Step by Step» предполагает поэтапное «шаг за шагом» усвоение программного материала, возможности обсудить свое понимание и видение проблемы с другими участниками образовательного процесса.

Ежедневно на уроках была организована работа в центрах активности. Учащиеся работали в каждом центре по 10 минут. По истечении времени звучал сигнал. Младшие школьники переходили из центра в центр по часовой стрелке. Такая организация учебного занятия позволила эффективно использовать время на уроке, а учащиеся смогли не устать и быть вовлеченными в деятельность и сохранить увлеченность в течение всего урока.

Для каждого центра активности были разработаны задания с использованием трех уровней: репродуктивного, алгоритмического, творческого. Если младший школьник затрудняется в выполнении какого-либо уровня, то предусмотрены коллективное обсуждение затруднений и помощь.

Основным отличительным признаком работы в экспериментальных группах было регулярное, планомерное и систематическое (от урока к уроку) использование групповых форм работы в центрах активности. При традиционной системе обучения групповая работа носит эпизодический характер.

Осуществляя экспериментальную деятельность, способствовали тому, что темы и цели урока учащиеся добывали сами, выполняя различные задания. Например: на доске записаны анаграммы, решив их, определите тему урока:

\begin{tabular}{l|l|l} 
КЗОА (коза) & АСЛИ (лиса) & РИГТ (тигр) \\
\hline
\end{tabular}

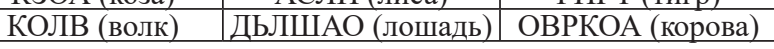

- Что объединяет эти слова?

- На какие группы их можно разделить?

- Почему говорят домашние животные?

- Назови диких животных.

- Какое самое главное отличие диких животных от домашних?

- Сегодня на уроке нам предстоит работа в центрах активности. Какие правила работы в центрах вы знаете?

Правила сотрудничества в группах на начальном этапе были разработаны совместно с детьми. Постоянное напоминание о необходимости соблюдения правил позволило учащимся достичь слаженности в работе, невзирая на трудности во взаимопонимании.

Изложенная система работы по технологии «Step by Step» ориентирована на формирование 
Никитина Е. С. Анализ развития международной образовательной программы...

умственных действий детей, обучение младших школьников способам выявления закономерностей и отношений, выполнение посильных обобщений, умение делать выводы.

\section{Результаты и обсуждение}

Для осуществления диагностики результативности обучения младших школьников с применением технологии «Step by Step» учащихся экспериментальной и контрольной групп в завершение формирующего эксперимента проведено повторное исследование академической успеваемости. Цель экспериментальной работы - выявить индивидуальные изменения успеваемости и качественной обученности младших школьников.

Задача исследования: доказать эффективность технологии «Step by Step» в повышении уровня академической успеваемости младших школьников. Исходя из теоретических выводов, результатов по изучению состояния проблемы успеваемости в начальной школе, были проведены контрольные работы по выявлению степени эффективности предложенных средств повышения качества знаний учащихся. Цель работы для учащихся 4-го класса: выявить соответствие знаний, умений и навыков требованиям государственного общеобязательного стандарта общего среднего образования. Результаты данной работы представлены в табл. 2.

Дадим качественную характеристику каждой группе.

\section{Экспериментальная группа}

Количество учащихся - 149 человек,

Коэффициент обученности $-0,71$.

Контрольная группа

Количество учащихся -148 человек,
Коэффициент обученности - 0,59.

Сравнительные результаты годового среза представлены на рис. 2.

Сравнивая результаты, отметим, что в экспериментальном классе количество двоек за контрольную работу уменьшилось на $50 \%$, уменьшилось количество оценок «3» с 60 человек до 40 (на $26 \%$ ); увеличилось количество оценок «4» с 52 человек до 61 (на $6 \%$ ); количество оценок «5» с 30 человек до 45 (на $10 \%$ ). В контрольном классе двоек за контрольную работу стало больше с 8 человек до 9 (увеличение на 0,6 \%); количество оценок «3» осталось на том же уровне (58 человек); уменьшилось количество оценок «4» с 52 человек до 51 (на $0,6 \%$ ); количество оценок «5» осталось неизменным - 30 человек.

\section{Заключение}

По результатам эксперимента можно сделать вывод, что ученикам начальной школы интересны уроки, проводимые по технологии «Step by Step». Занятия, разработанные по этой технологии, содействуют формированию коммуникативных навыков, воспитанию самостоятельности, помогают развитию самоорганизации и проявлению инициативы [17].

Для достижения целей, поставленных на данном уроке, необходимо находить методы и средства для решения задач, исходя из собственного жизненного опыта. Благодаря этому можно исключить такие неблагоприятные проявления традиционного обучения, как тревога из-за опасения получить отрицательную оценку, неуверенность в собственных силах.

Резюмируя данные исследования, можно сделать вывод, что технология «Step by Step» сущест-

Таблица 2

Результаты контрольного среза (итоговая контрольная работа)

\begin{tabular}{|c|c|c|c|c|c|c|c|c|}
\hline \multirow{2}{*}{ Группа } & \multirow{2}{*}{$\begin{array}{c}\text { Количество } \\
\text { учащихся } \\
\text { в группе }\end{array}$} & \multirow{2}{*}{$\begin{array}{l}\text { Количество учащихся, } \\
\text { выполнявших работу }\end{array}$} & \multicolumn{4}{|c|}{$\begin{array}{l}\text { Результат выполнения } \\
\text { работ }\end{array}$} & \multirow{2}{*}{ Успеваемость, \% } & \multirow{2}{*}{ Качество, \% } \\
\hline & & & $\ll 5 »$ & $\begin{array}{c}\mathrm{pa} \\
\ll 4 »\end{array}$ & एT & «2» & & \\
\hline $\mathrm{K} \Gamma$ & 148 & 148 & 30 & 51 & 58 & 9 & 94 & 59 \\
\hline ЭГ & 149 & 149 & 45 & 61 & 40 & 3 & 98 & 71 \\
\hline
\end{tabular}

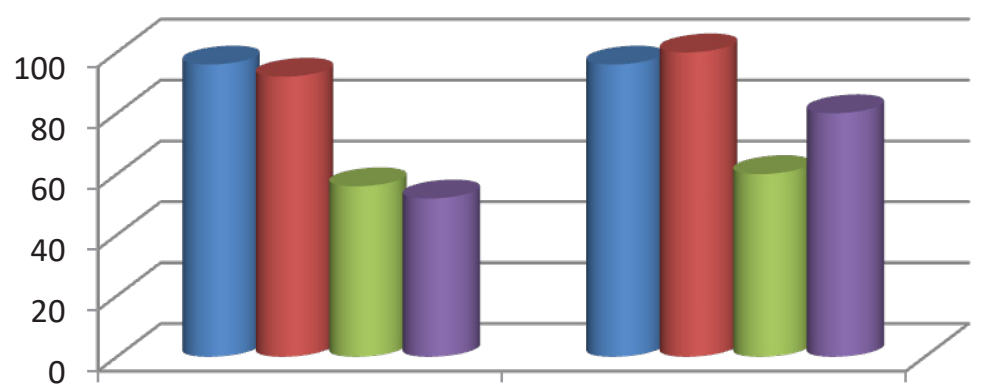

контрольный класс

экспериментальный класс успеваемость

успеваемость, год

качество знаний

в качество знаний, год

Рис. 2. Сравнительные результаты годовой контрольной работы учащихся экспериментальной и контрольной групп (май 2017 года) 
вует как результат объединенных усилий учителя и учеников, полученный в ходе проектирования, планирования, организации, ориентирования и корректирования действий для достижения итогов деятельности в благоприятных психолого-педагогических условиях.

\section{Список литературы}

1. Hemmeter M. L., Snyder P., Kinder K., Artman K. Impact of performance feedback delivered via electronic mail on pre-school teachers' use of descriptive praise // Early Childhood Research Quarterly. 2011. Vol. 26, is. 1. P. 96-109.

2. Хансен К. А., Кауфмманн Р. К., Уолш К. Б. Организация программы, ориентированной на ребенка: программа «Сообщество» - первая часть учебно-методического комплекта «Сообщество» / предисл. П. А. Коглин. М.: Гендальф, 2001. 276 с.

3. Skibbe L. E., Connor C., Morrison F. J., Jewkes A. M. Schooling effects on preschoolers' self-regulation, early literacy, and language growth // Early Childhood Research Quarterly. 2011. Vol. 26, is. 1. P. 42-49.

4. Trawick-Smith J., Dziurgot T. 'Good-fit' teacher-child play interactions and the subse-quent autonomous play of preschool children // Early Childhood Research Quarterly. 2011. Vol. 26, is. 1. P. 110-123.

5. Экспериментальная оценка MOT «Step by Step» в Казахстане и России // Отчет независимых экспертов. Алматы: Соросовский образоват. центр «Step by Step», 2004. С. 3-24.

6. Стандарты программы «Step by Step» и Стандарты для педагогов. Будапешт, 2002. $86 \mathrm{c}$.

7. Новый словарь иностранных слов. М.: Азбуковник, 2003. 148 с.

8. Глоссарий современного образования / под ред. В. И. Астаховой, А. Л. Сидоренко. Харьков: ОКО, 1998. 272 с.

9. Чошанов М. А. Гибкая психология проблемно-модульного обучения. М.: Народное образование, 1996. 160 c.

10. Количенко А. К. Энциклопедия педагогических технологий. СПб.: КАПО, 2000. 368 с.

11. Загвязинский В. И. Педагогическое предвидение. М.: Знание, 1987.

12. Никишина И. В. Инновационные педагогические технологии в школе. Волгоград: Учитель, 2007. С. 15.

13. Харламов И. Ф. Как активизировать учение школьников. 2-е изд., доп. и перераб. Мн.: Народная асвета, 1975. С. 208.

14. Алексеева Л. Н. Инновационные технологии как ресурс эксперимента // Учитель. 2004. № 3. С. 28.

15. Беспалько В. П. Педагогика и прогрессивные технологии обучения. М., 1995. С. 27.

16. Государственный общеобязательный стандарт образования Республики Казахстан от 23 августа 2012 года № 1080.

17. Волков И. П. Цель одна - дорог много. Проектирование процессов обучения. М.: Просвещение, 1990.

Никитина Елена Сергеевна, аспирант, Томский государственный педагогический университет (ул. Киевская, 60, Томск, Россия, 634061). E-mail: lukowskij@mail.ru

Материал поступил в редакциюю 22.04.2019.

DOI: $10.23951 / 1609-624 X-2020-1-16-23$

\section{ANALYSIS OF THE DEVELOPMENT OF INTERNATIONAL EDUCATIONAL PROGRAMMES AND TECHNOLOGY «STEP BY STEP» IN FOREIGN AND DOMESTIC THEORY AND PRACTICE}

\section{E. S. Nikitina}

Tomsk State Pedagogical University, Tomsk, Russian Federation

Introduction. The article is devoted to the study of the actual problem of development of the International educational program "Step by Step". The analysis of sociological, psychological, pedagogical, methodical works of famous domestic and foreign scientists and practitioners allowed to consider the historical and pedagogical aspects of the problem of development of this program, both abroad and in Russia and Kazakhstan.

Material and methods. The study was conducted on the basis of use of theoretical and empirical methods, the main of which was the analysis of interaction of participants of educational process and research is based on the lessons of science and math in elementary school. This work was carried out in three stages. The first stage was to determine the main theoretical and methodological provisions for the problem, analyzed the degree of its study, defined the General provisions. The second stage was to identify the features of the application of "Step by Step" in the classroom model of primary school. The third stage was to analyze the effectiveness of children's education using the technology "Step by Step".

Results and discussion. The comparative analysis allowed to consider the historical and pedagogical aspects of the problem of development of this program abroad, in Russia and Kazakhstan, as well as to justify the validity of the use of the term technology in relation to"Step by Step". The presented analysis of the concepts "technology", "educational technology", "pedagogical technology" proves the possibility of using the term "technology" with respect to "Step by 
Никитина Е. С. Анализ развития международной образовательной программын..

Step". Much attention is paid to the problem of social competence of the modern primary school student and its development in primary school.

Conclusion. Historical and pedagogical analysis of the development of "Step by Step" allows us to understand the essence and main idea of this technology. The goal of the educational process is the development of a child's personality, its individuality, uniqueness, based on beliefs and faith, with the features of own "internal world model", the structure of subjective experience, where the subject relations are based on the principles of individualization, cooperation, partnership and freedom of choice activities. The use of technology "Step by Step" increases the value of learning through a fundamentally new democratic approach that meets the standards of today and promotes dynamic cooperation of all parties to the educational process, during which there is an individual improvement.

Keywords: technology, international program, comparative analysis, «Step by Step», primary school.

\section{References}

1. Hemmeter M. L., Snyder P., Kinder K., Artman K. Impact of performance feedback delivered via electronic mail on pre-school teachers' use of descriptive praise. Early Childhood Research Quarterly, 2011, vol. 26, iss. 1, pp. 96-109.

2. Khansen K. A., Kaufmann R. K., Uolsh K. B. Organizatsiya programmy, orientirovannoy na rebenka: programma «Soobshchestvo» - pervaya chast' uchebno-metodicheskogo komplekta "Soobshchestvo». Predisloviye P. A. Koglin [Organization of the program focused on the child: the program «Community» - the first part of the educational and methodical set «Community». Foreword P. A. Coglin]. Moscow, Gendal'f Publ., 2001. 276 p. (in Russian).

3. Skibbe L. E., Connor C., Morrison F. J., Jewkes A. M. Schooling effects on preschoolers' self-regulation, early literacy, and language growth. Early Childhood Research Quarterly, 2011, vol. 26, is. 1, pp. 42-49.

4. Trawick-Smith J., Dziurgot T. 'Good-fit' teacher-child play interactions and the subsequent autonomous play of preschool children. Early Childhood Research Quarterly, 2011, vol. 26, iss. 1, pp. 110-123.

5. Eksperimental'naya otsenka MOT «Step by Step» v Kazakhstane i Rossii [Experimental evaluation of the ILO's «Step by Step» in Kazakhstan and Russia]. Otchet nezavisimykh ekspertov [Independent Expert Report]. Almaty, Sorosovskiy obrazovatel'nyy tsentr «Step by Step» Publ., 2004. Pp. 3-24 (in Russian).

6. Standarty programmy «Step by Step» $i$ Standarty dlya pedagogov [Standards of the program «Step by Step» and Standards for teachers]. Budapesht, 2002. 86 p. (in Russian).

7. Novyy slovar' inostrannykh slov [New dictionary of foreign words]. Moscow, Azbukovnik Publ., 2003. 148 p. (in Russian).

8. Glossariy sovremennogo obrazovaniya. Pod red. V. I. Astakhovoy i A. L. Sidorenko [Glossary of modern education]. Kharkov, OKO Publ., 1998. 272 p. (in Russian).

9. Choshanov M. A. Gibkaya psikhologiya problemno-modul'nogo obucheniya [Flexible psychology of problem-modular training]. Moscow, Narodnoye obrazovaniye, 1996. 160 p. (in Russian).

10. Kolichenko A. K. Entsiklopediya pedagogicheskikh tekhnologiy [Encyclopedia of pedagogical technologies]. Saint Petersburg, KAPO Publ., 2000. 368 p. (in Russian).

11. Zagvyazinskiy V. I. Pedagogicheskoye predvideniye [Pedagogical foresight]. Moscow, Znaniye Publ., 1987 (in Russian).

12. Nikishina I. V. Innovatsionnye pedagogicheskiye tekhnologii v shkole [Innovative pedagogical technologies in school]. Volgograd, Uchitel' Publ., 2007. P. 15 (in Russian).

13. Kharlamov I. F. Kak aktivizirovat' ucheniye shkol'nikov. Izd. 2-e, dop. i pererab. [How to activate schoolchildren's teaching]. Minsk, Narodnaya asveta Publ., 1975. P. 208 (in Russian).

14. Alekseyeva L. N. Innovatsionnye tekhnologii kak resurs eksperimenta [Innovative technologies as a resource of the experiment]. Uchitel', 2004, no. 3, pp. 28 (in Russian).

15. Bespal'ko V. P. Pedagogika i progressivnye tekhnologii obucheniya [Pedagogy and progressive learning technologies]. Moscow, 1995. P. 27 (in Russian).

16. Gosudarstvennyy obshcheobyazatel'nyy standart obrazovaniya Respubliki Kazakhstan ot 23 avgusta 2012 goda № 1080 [State compulsory education standard of the Republic of Kazakhstan dated August 23, 2012 No. 1080] (in Russian).

17. Volkov I. P. Tsel' odna - dorog mnogo. Proyektirovaniye protsessov obucheniya [One goal - many roads. Design of learning processes]. Moscow, Prosveshcheniye Publ., 1990 (in Russian).

Nikitina E. S., Tomsk State Pedagogical University (ul. Kiyevskaya, 60, Tomsk, Russian Federation, 634061).

E-mail: lukowskij@mail.ru 